\title{
Prevalência e sensibilidade de microrganismos isolados em uroculturas no Espirito Santo, Brasil
}

\author{
Prevalence and sensitivity of microrganisms in isolated urocultures in Espírito Santo, \\ Brazil
}

$\begin{array}{lr}\text { Recebido em: } & 29 / 10 / 2015 \\ \text { Aceito em: } & 28 / 12 / 2015\end{array}$
Ronaldo José FARIA; Patrícia Silva BAZONI; Carlos

Eduardo Faria FERREIRA

Faculdade de Filosofia, Ciências e Letras de Alegre. Rua Belo Amorim 100,

Centro. Alegre-ES CEP: 29500-000,Brasil.E-mail: ronaldojfaria@hotmail.com

\section{ABSTRACT}

The urinary tract infection (UTI) is one of the most frequent bacterial infections occurring in humans, and it is considered the second most frequent infection in the world. This work aims to identify and describe the prevalence and sensitivity of microorganisms isolated from urine cultures. A cross-sectional study was done involving the retrospective analysis of existing data in urine cultures logbooks performed between December of 2012 and April of 2013, in private laboratories of the south region of Espirito Santo. Logs from 413 positive urine cultures and their antibiotic susceptibility results were analyzed to obtain the prevalence of microorganisms and their sensitivity profiles. The analyzed data show that $87,9 \%$ belonged to female patients; the most common microorganism was Escherichia coli, detected in $71,0 \%$ of urine cultures. Regarding the tested antibiotics, ampicillin was the less active, inhibiting only $42,3 \%$ of organisms growth, followed by sulfamethoxazoletrimethoprim $(60,0 \%)$, cephalothin $(65,1 \%)$ and cefazolin $(69,7 \%)$. The frequency of the isolated uropathogenic organisms and their profile of sensitivity and resistance varied according to the region and the population studied.

Keywords: antibiotic; prevalence; resistance; infections; urinary tract

\section{RESUMO}

A infecção do trato urinário (ITU) é uma das mais frequentes infecções bacterianas que ocorrem no ser humano, sendo considerada a segunda infecção mais frequente mundo. Este trabalho teve como objetivo identificar e descrever o perfil de prevalência e de sensibilidade de microrganismos isolados em uroculturas. Foi realizado um estudo transversal que envolveu a análise retrospectiva de dados existentes em livros de registro de uroculturas realizadas no período de dezembro de 2012 a abril de 2013, em um laboratório de análises clínicas da rede particular de laboratórios da região sul do Estado do Espírito Santo. Foram analisadas 413 uroculturas positivas e os seus respectivos antibiogramas para a obtenção da prevalência de microrganismos e do seu perfil de sensibilidade. Das uroculturas analisadas, $87,9 \%$ pertenciam a pacientes do sexo feminino, e o uropatogênico mais prevalente foi a Escherichia coli, sendo detectada em $71,0 \%$ das uroculturas. Dos antimicrobianos testados, a ampicilina foi o que apresentou menor atividade contra os uropatogênicos, inibindo efetivamente o crescimento de apenas $42,3 \%$ dos agentes isolados, seguido do sulfametoxazol-trimetoprina $(60,0 \%)$, cefalotina $(65,1 \%)$ e cefazolina $(69,7 \%)$. A frequência do uropatogênico isolado e o seu perfil de sensibilidade e resistência varia de acordo com a região e população estudada.

Palavras-chave: antibiótico; prevalência; resistência bacteriana; infecções; trato urinário 


\section{INTRODUÇÃO}

A infecção do trato urinário (ITU) é uma das mais frequentes infecções bacterianas que ocorrem no ser humano, sendo considerada a segunda infecção mais frequente no mundo (1). Desenvolvem quando há invasão e multiplicação de microrganismos no sistema urinário (2). Os microrganismos podem alcançar o trato urinário e causar uma infecção urinária por três vias: a via ascendente (através da uretra), que é a mais frequente; a via hematogênica (devido à intensa vascularização do rim), e a via linfática (pelas conexões linfáticas entre o intestino e o rim) $(3,4)$.

De acordo com sua localização, as ITU são divididas em baixa (cistite, uretrite, prostatite e epididimite) e alta (pielonefrite e ureterite). Quanto a fatores agravantes e predisponentes, estas infecções são classificadas em ITU não-complicadas (quando não há anormalidade anatômica ou funcional do aparelho geniturinário, ocorrendo primariamente em mulheres jovens com vida sexual ativa) e ITU complicadas (quando há alguma anormalidade funcional ou estrutural do trato urinário, como no caso de procedimentos cirúrgicos, presença de cálculos renais ou prostáticos, doenças predisponentes que causam infecção renal como anemia falciforme, diabetes melittus e doença policística renal). Os principais grupos etários acometidos pela ITU são crianças (maior incidência até dois anos), mulheres com vida sexual ativa, e idosos (idade superior a 60 anos) (5).

No Brasil, a cada 1.000 consultas médicas realizadas, 80 são devidas ao desenvolvimento de infecção urinária (6). Vários microrganismos podem ocasionar ITU, porém na maioria dos casos, esta invasão ocorre por bactérias Gram-negativas, como a Escherichia coli, que é o agente etiológico mais comum (7). Dependendo do tipo de ambiente em que se adquiriu a ITU, na comunidade ou em serviços de saúde, o microrganismo causador irá variar na sua frequência (8). Em todo o mundo, a resistência bacteriana tem aumentado, sendo necessária a realização de estudos que informem sobre as taxas de prevalência e resistência de patógenos locais (9).

Vários métodos podem ser utilizados para a realização do diagnóstico das ITU, como o diagnóstico por imagem, utilização de fitas reagentes e análise do sedimento urinário. No entanto a utilização de uroculturas é o método mais indicado e considerado como padrão-ouro na investigação das ITU (10). Este método não só confirma a presença de infecções urinárias, mas também fornece meios para o isolamento e identificação do uropatógeno causador e a realização do antibiograma, que mostra o perfil de sensibilidade destes antimicrobianos (11).

As infecções urinárias devem ser tratadas de forma adequada, precoce e, idealmente, envolver o isolamento do microrganismo infectante, proporcionando tratamento específico e guiado (12). Mesmo sendo restrita a venda de antimicrobianos (retenção obrigatória da receita médica), esses medicamentos estão entre aqueles que mais são utilizados pelo ser humano de forma incorreta, levando ao desenvolvimento de resistência dos microrganismos aos mesmos (13).

O uso inadequado de antimicrobianos nas infecções urinárias é um grande fator de preocupação mundial, pois ocasiona um aumento da resistência bacteriana destes uropatógenos, podendo gerar cepas multiresistentes; a detecção de bactérias gram-negativas multirresistentes é emergente em várias partes do mundo, além do aumento dos custos para o sistema de saúde $(14,15)$.

Devido ao fato do tratamento das ITU ser muitas das vezes realizado de forma empírica, se torna necessário o conhecimento epidemiológico e do padrão de sensibilidade dos uropatógenos isolados em cada região e localidade, para que, assim, a seleção da conduta terapêutica seja realizada de forma racional. (7). Tendo isto em vista, o presente estudo teve como objetivo descrever a prevalência e o perfil de sensibilidade dos microrganismos isolados em uroculturas de um laboratório de análises clínicas da região sul do Estado do Espírito Santo.

\section{MATERIAIS E MÉTODOS}

Para o desenvolvimento deste trabalho, foi obtida, previamente, a aprovação no CEP (Comitê de Ética e Pesquisa) da FAFIA - Faculdade de Filosofia, Ciências e Letras de Alegre, sob o número de protocolo 1465/2013. Foi obtida, ainda, a autorização do proprietário da empresa onde foi realizada a pesquisa, sendo que a mesma não trouxe risco algum para a população estudada e ofereceu como benefício à conscientização sobre a importância do uso racional dos antimicrobianos.

Trata-se de um estudo transversal que envolveu a análise retrospectiva de dados existentes em livros de registro de uroculturas positivas realizadas no período de dezembro de 2012 a abril de 2013, de um laboratório pertencente a uma rede particular de laboratórios de análises clínicas. Este laboratório conta com postos de coleta em sete municípios: Guaçuí, Jerônimo Monteiro, São José do Calçado, Bom Jesus do Norte, Divino de São Lourenço e 
Ibitirama, sendo estes localizados na Região Sul do Espírito Santo, Brasil. Os resultados das uroculturas analisados neste estudo são provenientes de pacientes da comunidade, uma vez que este laboratório não recebe amostras de hospitais.

Foi considerada urocultura positiva aquela que apresentou crescimento maior que $100.000 \mathrm{UFC} / \mathrm{mL}$. Foi realizada a identificação do uropatógeno a partir do uso de provas bioquímicas específicas e, por último, foi obtido o antibiograma por meio da técnica de disco-difusão em Ágar Mueller-Hinton para os seguintes antimicrobianos: amicacina, imipeneno, ciprofloxacino, ceftriaxona, cefotaxima, cefazolina, cefalotina, sulfametoxazol+trimetoprima, ampicilina e amoxicilina+ácido clavulâmico. Foram analisadas 413 uroculturas positivas.

\section{RESULTADOS E DISCUSSÃO}

As uroculturas referiam-se predominantemente, a amostras de urina de indivíduos do sexo feminino (87,9\%). $\mathrm{O}$ uropatógeno mais identificado nas uroculturas positivas foi Escherichia Coli (71,0\%). Foi observada, ainda, a presença de outros agentes etiológicos, como Proteus sp $(12,1 \%)$, Staphylococcus sp (11,1\%), e outras enterobactérias, como Enterobacter sp., Klebsiella sp. e Pseudomonas sp., identificados em 5,8\% das uroculturas (Figura 1).

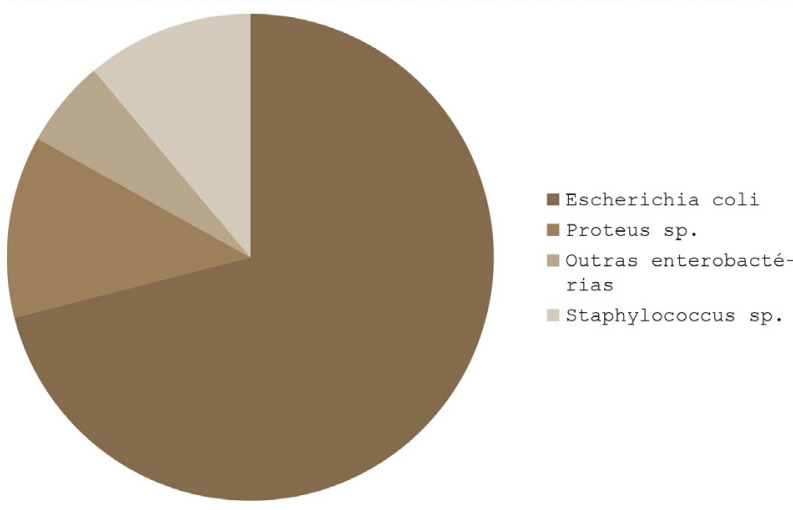

Figura 1 - Frequência de uropatógenos causadores de ITU na região Sul do Espírito santo, Brasil, no período de dezembro de 2012 a abril de 2013.

Os uropatógenos identificados se mostraram sensíveis sobre tudo ao imipeneno (97,3\% das amostras), amicacina $(96,4 \%)$, ceftriaxona $(82,1 \%)$ e cefotaxima $(78,6 \%)$. Entre os agentes orais comumente utilizados no tratamento de ITU, os patógenos mostraram sensibilidade para amoxicilina+ácido clavulânico em $77,5 \%$ das amostras, para o ciprofloxacino em $71,9 \%$, para o sulfametoxazol+trimetoprima em 60,0\%; e para a ampicilina em 42,3\% (Figura 2).
Em um estudo na cidade de Ponta Grossa (PR), foi observado que $70,0 \%$ das uroculturas positivas pertenciam a pacientes do sexo feminino (16). No Estado da Paraíba, Campina Grande, 85,2\% dos indivíduos acometidos com infecção no trato urinário eram do gênero feminino (17). Este predomínio também pode ser observado em um estudo em São Luís (MA), onde mulheres representaram 68,8\% dos casos (18). Isto representa um indicativo de que a população feminina é uma das principais acometidas pelas ITU em diferentes regiões do país.

Foi observado que a frequência do uropatógeno causador da ITU varia de acordo com a região estudada, mas a prevalência se mantém semelhante, como mostra o estudo na cidade de Rio Grande (RS), onde, em 66,2\% das 957 uroculturas positivas, foi isolada a bactéria Escherichia coli (19). Um estudo na cidade de Santa Maria, também no Estado do Rio Grande do Sul, mostrou a Escherichia coli como responsável em $60,1 \%$ das ITU (20). Este uropatógeno também prevaleceu em $67,9 \%$ dos casos na cidade de Goiânia (GO) (14). Na cidade de Belo Horizonte (MG), após a análise de mais de 100.000 uroculturas positivas, foi observado que Escherichia coli foi a mais prevalente entre os uropatógenos (21). Mesmo sendo menos prevalentes, existem outras bactérias responsáveis pelas ITU, que em muitos casos, geram graves infecções, necessitando de uma atenção especial e um tratamento efetivo.
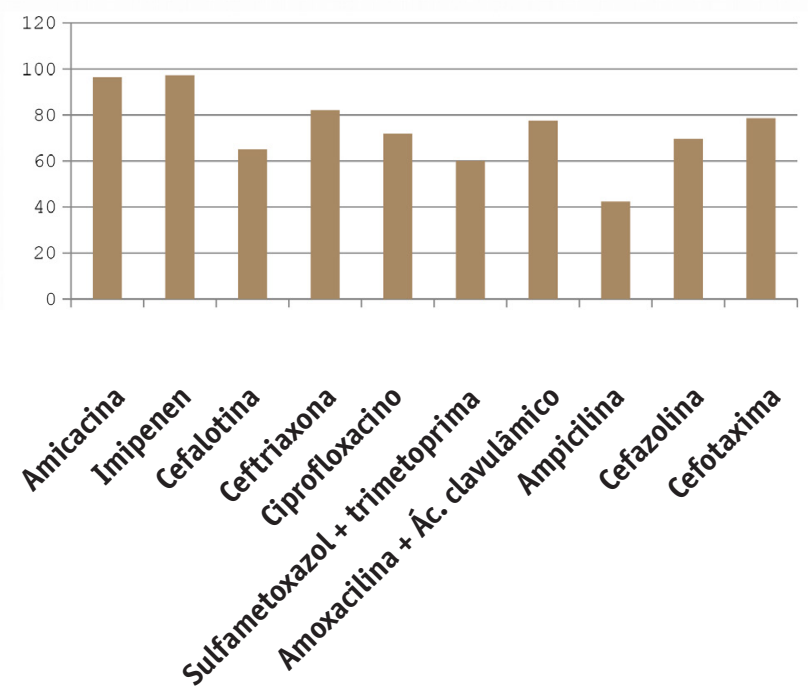

Figura 2 - Perfil de sensibilidade microbiana de infecções do trato urinário de indivíduos moradores de municípios pertencentes à região Sul do Estado do Espírito Santo, Brasil (dezembro, 2012-abril, 2013)

Em um estudo na cidade de Maceió (AL), os patógenos causadores de ITU isolados foram sensíveis ao ciprofloxacino, em $84,6 \%$, ao sulfametoxazol com trimetoprima, em $31,6 \%$, e à ampicilina, em $32,0 \%$, medicamentos de pri- 
meira escolha para este tipo de infecção (22). Em Brasília (DF), após análise de 2.433 uroculturas positivas em um período de cinco anos, foi observada sensibilidade de 50,6\% dos isolados ao sulfametoxazol com trimetoprima, $90,9 \%$ ao ciprofloxacino e $23,4 \%$ à ampicilina (6). Na cidade de Santa Cruz do Sul (RS), após a análise de 1.273 amostras positivas, foi observado um perfil de sensibilidade de $98,0 \%$ ao ciprofloxacino, $98,4 \%$ à cefalotina, $80,8 \%$ ao sulfametoxazol com trimetoprima e 31,0\% à ampicilina (23).

Por outro lado, em umo estudo na cidade de Recife (PE), a ampicilina inibiu o crescimento de forma efetiva em apenas $32,9 \%$ das uroculturas, enquanto sulfametoxazol com trimetoprima foi efetivo em 59,2\%. A amoxacilina associada com ácido clavulânico inibiu o crescimento de $67,7 \%$ dos isolados e para o ciprofloxacino, esta porcentagem foi equivalente a $83,9 \%$ (24).

\section{REFERÊNCIAS}

1. Lopes HV, Tavares W. Diagnóstico das infecções do trato urinário. Rev Assoc Med Bras. 2005; 51(6):301-312. DOI: $10.1590 / \mathrm{S} 0104-42302005000600008$

2. Silveira SA, Araújo MC, Fonseca FM, Okura MH, Oliveira ACS. Prevalência e suscetibilidade bacteriana em infecções do trato urinário de pacientes atendidos no Hospital Universitário de Uberaba. Rev Bras de Analis Clínicas. 2010; 42(3):157-160.

3. Amadeu ARORM, Sucupira JS, Jesus RMM, Rocha MLP. Infecções do Trato Urinário: análise da frequência e do perfil de sensibilidade da Escherichia coli como agente causador dessas infecções. Rev Bras de Anális Clínicas. 2009; 41(4):275-7.

4. Grabe M, Bjerklund JEB, Botto H, Çek M, Naber KG, Tenke P, Wagenlehner F. Guidelines on Urological Infections. Associação Europeia de Urologia. 2010. Disponível em: <http://www.uroweb.org/gls/pdf/Urological\%20 Infections\%202010.pdf>. Acesso em: 19 maio 2013. 5. ANVISA Agência Nacional de Vigilância Sanitária. Manual de microbiologia clínica para o controle de infecção em serviços de saúde. Brasília: Ministério da Saúde; 2004.

6. Pires MCS, Frota KS, Martins POJ, Corrêa AF, Escalante JJC, Silveira CA. Prevalência e suscetibilidades bacterianas das infecções comunitárias do trato urinário, em Hospital Universitário de Brasília, no período de 2001 a 2005. Rev Soc Bras Med Tropic. 2007; 40(6):643-647. DOI: $10.1590 / \mathrm{S} 003786822007000600009$

7. Heilberg IP, Schor N. Abordagem diagnóstica e terapêutica na infecção do trato urinário - ITU. In: Rev Assoc Med Bras. 2003; 49(1):109-16. DOI: 10.1590/S010442302003000100043

8. Muller EV, Santos DF, Corrêa NAB. Prevalência de microrganismos em infecções do trato urinário de pacientes atendidos no laboratório de análises clínicas da Universidade Paranaense - Umuarama - PR. Rev Bras Anális Clín. 2008; 40(1):35-37.

\section{CONCLUSÃO}

A frequência do uropatógeno causador das ITU e o seu perfil de sensibilidade e resistência variam de acordo com a região e a população estudada. Dessa forma, a implantação do diagnóstico correto juntamente com o emprego racional dos antimicrobianos são medidas que se tornam indispensáveis e essenciais para o sucesso no tratamento, evitando assim o aumento da resistência bacteriana e proporcionando menores gastos para o paciente e as instituições.

\section{AGRADECIMENTOS}

À Faculdade de Filosofia Ciências e Letras de Alegre, ao Laboratório Kashima, e a todos que de forma direta ou indireta contribuíram para a realização deste estudo.

9. MAIA ASC. Etiologia das infecções urinárias e susceptibilidade aos antibióticos. Aveiro, Portugal. Dissertação (Mestrado em Microbiologia). Universidade de Aveiro; 2010.

10. Santana TCFS, Pereira EMM, Monteiro SG, Mônica SM, Turri RJG, Figueiredo PMS. Prevalência e resistência bacteriana aos agentes antimicrobianos de primeira escolha nas infecções do trato urinário no município de São Luís-MA. Rev Patol Trop. 2012; 41(4):409-418.

11. Martins F, Vitorino J, Abreu A. Avaliação do perfil de susceptibilidade aos antimicrobianos de microrganismos isolados em urinas na região do Vale do Sousa e Tâmega. Acta Med Port. 2010; 23(4):641-646.

12. Mendo A, Antunes J, Costa MC, Pereira PM, Monteiro C, Gomes CF, Gomes JF. Frequência de Infecções Urinárias em Ambulatório - dados de um laboratório de Lisboa. Rev Lusóf Ciênc Tecnol Saúde. 2008; 5(2):216-223.

13. OMS. Organização Mundial da Saúde. O uso de antimicrobianos. [acesso em 20 de maio 2013]. Disponível em: http://www.who.int/drugresistance/use/Antimicrobial_ Use/en/.

14. Poletto KQ, Reis C. Suscetibilidade antimicrobiana de uropatógenos em pacientes ambulatoriais na Cidade de Goiânia, GO. Rev Soc Bras Med Trop. 2005; 38(5):416420. DOI: $10.1590 / \mathrm{S} 0037-86822005000500011$

15 - OMS. Organização Mundial da Saúde. A resistência antimicrobiana. [acesso em 20 de maio 2015]. Disponível em: http://www.who.int/drugresistance/documents/surveillancereport/en/

16. Bail L, Ito CAS, Esmerino LA. Infecção do trato urinário: comparação entre o perfil de susceptibilidade e a terapia empírica com antimicrobianos. Rev Bras Anális Clín. 2006; 38(1):51-56.

17. Costa LC, Belém LF, Silva PMF, Pereira HS, Silva EDJ, Leite TR, Pereira GJS. Infecções urinárias em pacientes ambulatoriais: prevalência e perfil de resistência aos antimicrobianos. Rev Bras Anális Clín. 2010; 42(3):175-180. 
18. Santana TCFS, Maião RC, Monteiro SG, Carmo MS, Figueiredo PMS. Perfil de resistência de Escherichia coli e Klebsiella spp isoladas de urocultura de comunidade do município de São Luis-MA no período de 2005-2008. Rev Pat Trop. 2012; 41(3):295-303.

19. Koch CR, Ribeiro JC, Schnor OH, Zimmermann BS, Muller FM, Agostin JD, Machado V, Zhang L. Resistência antimicrobiana dos uropatógenos em pacientes ambulatoriais, 2000-2004. Rev Soc Bras Med Tropic. 2008; 41(3):277281. DOI: $10.1590 / \mathrm{S} 0037-86822008000300010$.

20. Santos RCV, Klein DR, Duarte M. Prevalência e perfil de resistência de microrganismos em infecções do trato urinário diagnosticados em pacientes ambulatoriais em Santa Maria, Rio Grande do Sul. Rev Bras Anális Clín. 2009; 41(4):311-314.

21. SMSA. Secretaria Municipal de Saúde de Belo Horizonte. Protocolos de Atenção a Saúde: Infecção Urinária. Disponível em: http://portalpbh.pbh.gov.br/pbh/ecp/files.do?e- vento $=$ download\&urlArqPlc=protocolo_infeccao_urinaria CP.pdf. Acesso em: 06 de maio 2015

22. Leite AB, Lima ARV, Barros HCS, Leite RB, Araújo IC, Tadeo MIVN, Lopéz AMQ. Freqüência de bactérias gram -negativas em uroculturas de pacientes ambulatoriais, do sistema único de saúde (SUS) de Maceió (AL), e sua sensibilidade a antibióticos. Rev Bras Anális Clín. 2009; 41(1);15-20.

23. Rieger A, Ferrugem F, Horta G, Oliveira CF, Carneiro M, Horta JÁ. Prevalência de patógenos bacterianos e susceptibilidade aos antimicrobianos em infecções do trato urinário de amostras ambulatoriais. Rev Bras Anális Clín. 2009; 41(2):87-89.

24. Magalhães V, Farias RB, Agra R, Lima ALMA, Etiologia e perfil de resistência das bactérias isoladas a partir de uroculturas oriundas de mulheres acima dos 18 anos. Rev Bras Med. 2008.11-16. 